\title{
No. 391
}

Pacific Rim Geological Consulting, Inc. 2011, Core descriptions, photographs and thin section photomicrographs from the Humble Oil DDH-04, 07, 08, 09, 10, 11, 12, 14, 15, 16, and 17 boreholes, Kemuk Mountain Prospect, Dillingham Quadrangle

\section{DVD available upon request (266 photos, 1.29 GB)}

$\therefore \quad$ Received J anuary, 2011

All data reports may be downloaded free of charge from the DGGS website. 


\section{Kemuk Core Inspection Methodology}

From May 12-14, 2010 on behalf of a client, PRGCl inspected the Kemuk Mountain core stored at the GMC facility in Eagle River, Alaska.

It was unlikely that all 8,000 feet of Kemuk Mountain core (17 holes) stored at the GMC could be inspected during the short time allotment at the GMC, so we prioritized the effort. Data bases indicated that five drill holes, $\mathrm{H04}, \mathrm{HO}, \mathrm{H08}, \mathrm{H09}$, and $\mathrm{H} 12$, contained known copper mineralization. Two of these drill holes, $\mathrm{H} 07$ and $\mathrm{H} 09$, were drilled to a total depth of two thousand $(2,000)$ feet each and constitute just under 50 percent of all the core available for inspection. Core from drill hole H09 (76 boxes), was first examined, followed by core from $\mathrm{H} 07$ (62 boxes). PRGCI then examined core from drill holes $\mathrm{HO} 4$ ( 4 boxes), $\mathrm{H} 08$ (12 boxes), and H12 (15 boxes). Our priorities after this was to examine core from holes that stepped out from the center of the Kemuk intrusion, including examining drilling that penetrated country rock. We also examined drill hole H16 ( 8 boxes), hole H12 (15 boxes), and hole H17 ( 1 box). We finished off examining skeleton cores from drill holes $\mathrm{H} 10, \mathrm{H} 11, \mathrm{H} 14$, and $\mathrm{H} 15$. Due to time limitations, the writer (Bundtzen) did not examine core from drill holes $\mathrm{H} 13, \mathrm{HO2}, \mathrm{H05}, \mathrm{HO6}$, and $\mathrm{H} 03$.

Fairly complete logs from the 1950s Humble exploration program exist for drill holes H07-to-H17, but not for the other drill holes (see Appendix A; Whaley and Bray, 1959). Sporadic assay data also exist for drill holes H07-to-H17 (see Appendix B; Whaley and Bray, 1959) and for some selected intervals completed by Alaska Earth Sciences (AES) for portions of drill core. This information was routinely examined during the inspection of the core. The Niton ${ }^{\mathrm{TM}}$ analyzer used in the study was unable to record and store data that was acquired during individual scans. In addition there seemed to be significant variance in results. For example, portions of core examined twice appeared to have different metal value readings although anomalous those areas of interest scanned remained anomalous in metal content. During discussions of core results, PRGCl makes reference to Niton results qualitatively e.g., low, medium, and high results of specific metals identified (see Table 2 for further information).

The work proceeded as follows: a) Bundtzen inspected the logged core and created notations that appear in Table 2; b) Tina Laird photographed core; and c) others, including GMC personnel, assisted in the re-boxing re-storage of core. Upon consultation and approval by GMC staff, PRGCl selected sections of core to be made into $25 \times 40 \mathrm{~mm}$ thin sections, which were examined during this study. Prior to our investigation, the Kemuk core boxes were out-of sequence. Tom Bundtzen and Tina Laird created photomicrographs of the thin sections. At one site, 205029 a plug was made but a thin section was not produced. By agreement between PRGCl and the GMC, the core facility will have: 1) the core boxes completely in order; 2 ) a selected suite of thin sections and plugs; and 3) a photographic collection of all core boxes. 
Table 1 Roster of Kemuk Property Core, Southwest Alaska

\begin{tabular}{|c|c|c|c|c|}
\hline Drill Hole & $\begin{array}{c}\text { Bedrock Intercept } \\
\text { from surface (ft) }\end{array}$ & $\begin{array}{c}\text { Bottom of Hole } \\
\text { (ft) }\end{array}$ & $\begin{array}{c}\text { Total bedrock } \\
\text { record in drill hole } \\
\text { (ft) }\end{array}$ & $\begin{array}{c}\text { Total Number of } \\
\text { Core Boxes }\end{array}$ \\
\hline H02 & 170 & 487 & 317 & 2 \\
\hline H03 & 360 & 1,002 & 642 & 9 \\
\hline H04 & 296 & 468 & 172 & 0 \\
\hline H05 & 149 & 149 & 422 & 10 \\
\hline H06 & 265 & 687 & 1,845 & 63 \\
\hline H08 & 155 & 2,000 & 353 & 12 \\
\hline H09 & 224 & 577 & 1,766 & 77 \\
\hline H10 & 234 & 2,000 & 332 & 11 \\
\hline H11 & 200 & 532 & 341 & 14 \\
\hline H13 & 159 & 500 & 383 & 15 \\
\hline H14 & 254 & 637 & 338 & 12 \\
\hline H15 & 330 & 668 & 409 & 12 \\
\hline H16 & 91 & 500 & 167 & 7 \\
\hline H17 & 470 & 637 & 293 & 8 \\
\hline TOTALS/Average & Average=258 & Total=11,975 & Total=7,999 & \\
\hline
\end{tabular}

1) Skelton cores for drill holes $\mathrm{H} 8,10,11,13,14,15$, and 16 occur in three additional boxes. 
Table 2 Abbreviated Notes Taken by Pacific Rim Geological Consulting, Inc During Examination of Kemuk Core, May 12-14, 2010 @ Geological Materials Center (GMC), Eagle River, Alaska

\begin{tabular}{|c|c|c|c|c|c|c|c|}
\hline Drill Hole & Box \# & $\begin{array}{l}\text { Interval } \\
\text { (Feet) }^{(1)}\end{array}$ & Rock Type(s) Present ${ }^{(2)}$ & $\begin{array}{l}\text { Estimated } \\
\text { Core } \\
\text { Recovery }^{(3)}\end{array}$ & $\begin{array}{l}\text { Estimated } \\
\text { Magnetite } \\
\text { Content }^{(4)}\end{array}$ & $\begin{array}{c}\text { Alteration or } \\
\text { Mineralization Present }^{(5)}\end{array}$ & $\begin{array}{l}\text { Niton Results } \\
\text { (AES Analyses) }^{(6)}\end{array}$ \\
\hline H09 & $1 \mathrm{~A}$ & $234-239$ & $\begin{array}{l}\text { Pyroxene gabbro, with patches of } \\
\text { pyroxenite; dikes cut gabbro }\end{array}$ & 100 & Moderate & $\begin{array}{l}\text { Disseminated sulfides @ } 235.2 \\
\text { and } 238.0 \text { feet }\end{array}$ & NA \\
\hline H09 & $1 B$ & $239-259$ & $\begin{array}{l}\text { Pyroxene gabbro with feldspar-bearing } \\
\text { dikes }\end{array}$ & 100 & Moderate & $\begin{array}{l}\text { Pyrite along high angle } \\
\text { fractures }\end{array}$ & NA \\
\hline H09 & 2 & $259-281$ & Gabbro and fine grained andesite? & $75-100$ & Moderate & $\begin{array}{l}\text { Stockwork like high angle } \\
\text { fractures with pyrite }\end{array}$ & High V; moderate Ti; \\
\hline H09 & 3 & $181-301$ & $\begin{array}{l}\text { Pyroxene gabbro cut by pegmatoidal } \\
\text { feldspar veinlets }\end{array}$ & $90-100$ & Moderate & NA & NA \\
\hline H09 & 4 & $301-325$ & Pyroxene gabbro with mica-rich veins & 100 & Moderate & Sulfides in vertical veinlet & Moderate Bi and Mo \\
\hline H09 & 5 & $325-349$ & $\begin{array}{l}\text { Gabbro but transition to pyroxenite @ } 344 \\
\text { feet. }\end{array}$ & 100 & High & NA & $\begin{array}{c}\text { Moderate V Moderate } \\
\text { Mo @348 feet }\end{array}$ \\
\hline H09 & 6 & $349-372$ & $\begin{array}{c}\text { Back to gabbro @ } 353 \mathrm{ft} \text {; then back to } \\
\text { pyroxenite @ } 368 \mathrm{ft}\end{array}$ & $90-100$ & High & $\begin{array}{l}\text { Pyrite-kaolinite-chlorite } \\
\text { alteration with felsic veinlets }\end{array}$ & $\begin{array}{l}\text { Moderate Mo and Bi } \\
@ 356 \text { feet }\end{array}$ \\
\hline H09 & 7 & $372-406$ & Gabbro with dark andesite dikes & 100 & Moderate & $\begin{array}{l}\text { Trachy-andesite dikelets @ } \\
404 \mathrm{ft} .\end{array}$ & NA \\
\hline H09 & 8 & $406-438$ & $\begin{array}{l}\text { Gabbro with 8-10\% magnetite-rich dike @ } \\
418 \text { and } 425 \text { feet. }\end{array}$ & 100 & High & NA & $\begin{array}{c}\text { Moderate V and Ni @ } \\
425 \text { feet. }\end{array}$ \\
\hline H09 & 9 & $438-460$ & Gabbro with andesite dikes & 100 & High & $\begin{array}{l}\text { Xenolith of clinopyroxenite in } \\
\text { gabbro }\end{array}$ & High V @ 444 feet. \\
\hline H09 & 10 & $460-483$ & $\begin{array}{l}\text { Pyroxenite with 'felsic bands' and } \\
\text { hornblende-bearing dikelets }\end{array}$ & 100 & High & $\begin{array}{c}\text { Epidote-calcite-feldspar } \\
\text { veinlets trace chalcopyrite? }\end{array}$ & $\begin{array}{l}\text { High V moderate Pd, } \\
\text { and moderate Mo @ } \\
463 \text { feet. }\end{array}$ \\
\hline H09 & 11 & $483-513$ & $\begin{array}{l}\text { Irregular patches of diorite-gabbro in } \\
\text { pyroxenite; Thin section } 205001 @ 486 \mathrm{ft} \text {. }\end{array}$ & 100 & High & $\begin{array}{l}\text { Pervasive-feldspar-biotite- } \\
\text { sericite veins }\end{array}$ & NA \\
\hline H09 & 12 & 513-535 & Massive fine grained pyroxenite & 100 & High & NA & NA \\
\hline H09 & 13 & $535-558$ & $\begin{array}{l}\text { Massive fine grained pyroxenite; with } \\
\text { pegmatoid schlieren }\end{array}$ & 100 & High & Euhedral apatite grains & NA \\
\hline H09 & 14 & $558-581$ & $\begin{array}{l}\text { Massive fine grained pyroxenite; but with } \\
\text { patches of epidote alteration; } \\
\text { Thin section } 205002 @ 563 \text { feet. }\end{array}$ & 100 & High & Propylitic & NA \\
\hline
\end{tabular}




\begin{tabular}{|c|c|c|c|c|c|c|c|}
\hline Drill Hole & Box \# & $\begin{array}{l}\text { Interval }^{(\text {Feet }}{ }^{(1)} \\
\text { (F) }^{\text {In }}\end{array}$ & Rock Type(s) Present ${ }^{(2)}$ & $\begin{array}{l}\text { Estimated } \\
\text { Core } \\
\text { Recovery }^{(3)}\end{array}$ & $\begin{array}{l}\text { Estimated } \\
\text { Magnetite } \\
\text { Content }^{(4)}\end{array}$ & $\begin{array}{c}\text { Alteration or Mineralization } \\
\text { Present }\end{array}$ & $\begin{array}{l}\text { Niton Results } \\
\text { (AES Analyses) }^{(6)}\end{array}$ \\
\hline H09 & 15 & $581-603$ & Pyroxenite & 100 & High & $\begin{array}{l}\text { Chlorite selvages along } \\
\text { fractures }\end{array}$ & NA \\
\hline HO9 & 16 & $603-627$ & $\begin{array}{l}\text { Fine grained pyroxenite with thin andesite } \\
\text { dikes }\end{array}$ & 100 & Moderate & $\begin{array}{l}\text { Trace pyrite along high angle } \\
\text { fractures }\end{array}$ & NA \\
\hline HO9 & 17 & $627-649$ & $\begin{array}{l}\text { Fine grained pyroxenite with thin andesite } \\
\text { dikes }\end{array}$ & 100 & $\begin{array}{l}\text { Moderate to } \\
\text { Low }\end{array}$ & $\begin{array}{c}\text { epidote-carbonate veinlets @ } \\
645-648\end{array}$ & NA \\
\hline H09 & 18 & $649-671$ & $\begin{array}{l}\text { Fine grained pyroxenite but with low angle } \\
\text { granitic dikelets @ } 649 \text { and } 653 \mathrm{ft} .\end{array}$ & 100 & Moderate & Granitic dikelets & NA \\
\hline H09 & 19 & $671-693$ & $\begin{array}{l}\text { Pyroxenite with intervals of fine grained } \\
\text { andesite dikes }\end{array}$ & 100 & Moderate & $\begin{array}{c}\text { Shearing and felsic veinlets @ } \\
673-674 \mathrm{ft} . ; 685-687 \mathrm{ft} .\end{array}$ & High Ti \\
\hline H09 & 20 & $693-717$ & $\begin{array}{c}\text { Sheared andesite dike at } 714-717 \mathrm{ft} \text {; rest is } \\
\text { clinopyroxenite }\end{array}$ & 100 & Moderate & NA & NA \\
\hline H09 & 21 & $717-738$ & $\begin{array}{l}\text { Pyroxenite with abundant andesite } \\
\text { dikelets; some with pyrite, chalcopyrite } \\
\text { Thin section } 205003 \text { @ } 735 \text { feet. }\end{array}$ & $90-100$ & Moderate & $\begin{array}{l}\text { Pyrite and chalcopyrite along } \\
\text { high angle fractures }\end{array}$ & $\begin{array}{l}\text { High Cu ; High W; and } \\
\text { High V @ 735-737 feet. }\end{array}$ \\
\hline H09 & 22 & $738-761$ & $\begin{array}{c}\text { Pyroxenite with abundant andesite } \\
\text { dikelets; some with disseminated pyrite } \\
\text { and chalcopyrite }\end{array}$ & 100 & High & $\begin{array}{l}\text { Pyrite and chalcopyrite along } \\
\text { high angle fractures }\end{array}$ & High Cu @ 745 feet.; \\
\hline H09 & 23 & $761-784$ & Clinopyroxenite & 100 & Moderate & $\begin{array}{c}\text { Very minor disseminated } \\
\text { pyrite }\end{array}$ & NA \\
\hline H09 & 24 & $784-808$ & $\begin{array}{l}\text { Clinopyroxenite with thin andesite dikes } \\
\text { Thin section } 205004 \text { @ } 787 \text { feet. }\end{array}$ & 100 & Moderate & $\begin{array}{c}\text { Disseminated pyrite in } \\
\text { fractures }\end{array}$ & High Cu @ 787 feet. \\
\hline H09 & 25 & $808-829$ & Sheared clinopyroxenite with felsic patches & 100 & Low & $\begin{array}{l}\text { Chlorite fractures with } \\
\text { disseminated pyrite }\end{array}$ & NA \\
\hline H09 & 26 & $829-851$ & $\begin{array}{l}\text { Sheared clinopyroxenite with felsic patches } \\
\text { Thin section } 205005 @ 837 \text { feet. }\end{array}$ & 100 & Low & $\begin{array}{l}\text { Chlorite fractures with } \\
\text { disseminated pyrite }\end{array}$ & NA \\
\hline H09 & 27 & $851-875$ & $\begin{array}{c}\text { Coarse, biotite-rich clinopyroxenite with } \\
\text { thin andesite dikes }\end{array}$ & 100 & Moderate & NA & NA \\
\hline $\mathrm{HO9}$ & 28 & $875-898$ & Coarse, biotite-rich clinopyroxenite & 100 & Moderate & NA & NA \\
\hline H09 & 29 & $898-918$ & Coarse clinopyroxenite but without biotite & 100 & Moderate & NA & NA \\
\hline
\end{tabular}




\begin{tabular}{|c|c|c|c|c|c|c|c|}
\hline Drill Hole & Box \# & $\begin{array}{l}\text { Interval }^{(1)} \\
\text { (Feet) }^{(1)}\end{array}$ & Rock Type(s) Present ${ }^{(2)}$ & $\begin{array}{l}\text { Estimated } \\
\text { Core }^{(3)} \\
\text { Recovery }^{(3)}\end{array}$ & $\begin{array}{l}\text { Estimated } \\
\text { Magnetite } \\
\text { Content }^{(4)}\end{array}$ & $\begin{array}{l}\text { Alteration or Mineralization } \\
\text { Present }^{(5)}\end{array}$ & $\begin{array}{l}\text { Niton Results } \\
\text { (AES Analyses) }^{(6)}\end{array}$ \\
\hline H09 & 30 & $918-941$ & $\begin{array}{c}\text { Clinopyroxenite with felsic-patches with } \\
\text { porphyry clast @ } 929 \mathrm{ft} . \\
\text { Thin Section } 205006 @ 931 \text { feet. }\end{array}$ & 100 & Moderate & $\begin{array}{l}\text { Chalcopyrite, bornite and } \\
\text { malachite @ } 929 \mathrm{ft} . ;\end{array}$ & $\begin{array}{l}\text { High Cu @ 929-930 } \\
\text { feet. }\end{array}$ \\
\hline H09 & 31 & $941-964$ & Coarse clinopyroxenite but without biotite & 100 & Moderate & $\begin{array}{l}\text { Epidote-calcite-chrysocolla @ } \\
949 \text { feet }\end{array}$ & High Cu @ 949 feet. \\
\hline H09 & 32 & $964-987$ & Coarse grained clinopyroxenite & 100 & Moderate & $\begin{array}{l}\text { Abundant epidote alteration in } \\
\text { groundmass (Propylitic) }\end{array}$ & NA \\
\hline $\mathrm{H} 09$ & 33 & $987-1011$ & Biotite-rich clinopyroxenite & 100 & Moderate & Chrysocolla @ 1005 feet & Moderate $\mathrm{Cu}$ \\
\hline H09 & 34 & $1011-1034$ & $\begin{array}{l}\text { Fine grained clinpyroxenite; then to coarse } \\
\text { grained version @ } 1031 \text { feet. }\end{array}$ & $90-100$ & Moderate & $\begin{array}{l}2.0 \text { feet altered zone } 1032- \\
1034 \mathrm{ft} . ; \text { clots of epidote }\end{array}$ & NA \\
\hline H09 & 36 & $1057-1079$ & $\begin{array}{c}\text { Sheared clinopyroxenite; core more broken } \\
\text { up than previous record }\end{array}$ & 100 & $\begin{array}{l}\text { Moderate to } \\
\text { High }\end{array}$ & NA & NA \\
\hline $\mathrm{H} 09$ & 37 & $1079-1102$ & Coarse grained clinopyroxenite & 100 & High & Vertical chlorite veins & NA \\
\hline $\mathrm{H} 09$ & 38 & $1102-1125$ & Biotite-rich clinopyroxenite & 100 & High & NA & NA \\
\hline H09 & 39 & $1125-1148$ & $\begin{array}{l}\text { Coarse biotite clinpyroxenite with andesite } \\
\text { dikelets }\end{array}$ & 100 & High & Pegmatoid zone @ 1146 feet. & $\begin{array}{l}\text { (272840-847 but } \\
\text { negative results) }\end{array}$ \\
\hline H09 & 40 & $1148-1172$ & $\begin{array}{l}\text { Coarse biotite clinpyroxenite with andesite } \\
\text { dikelets }\end{array}$ & 100 & High & NA & $\begin{array}{l}\text { (272848-849-no } \\
\text { anomalies) }\end{array}$ \\
\hline H09 & 41 & $1172-1195$ & $\begin{array}{l}\text { Biotite clinpyroxenite with andesite } \\
\text { dikelets }\end{array}$ & 95 & High & $\begin{array}{c}\text { Vertical chlorite fracture } \\
\text { alteration stockwork @1190- } \\
92 \mathrm{ft} .\end{array}$ & $\begin{array}{l}\text { Moderate Zn @ 1190- } \\
1192 \text { feet. } \\
\text { (272851-852; no } \\
\text { anomalies) }\end{array}$ \\
\hline H09 & 42 & $1195-1219$ & $\begin{array}{l}\text { Clinopyroxenite with granodiorite dikes } \\
\text { Thin section of gd dike: } 205007 @ 1213 \mathrm{ft} \text {. }\end{array}$ & 100 & High & $\begin{array}{l}\text { Numerous thin high angle } \\
\text { chlorite fractures }\end{array}$ & $\begin{array}{l}\text { Moderate Zn @1213 } \\
\text { feet. }\end{array}$ \\
\hline H09 & 43 & $1219-1241$ & $\begin{array}{l}\text { Fine grained clinopyroxenite with } \\
\text { increasing magnetism }\end{array}$ & 100 & High & NA & $\begin{array}{c}\text { (272853-854; no } \\
\text { anomalies) }\end{array}$ \\
\hline H09 & 44 & $1241-1264$ & Fine grained clinopyroxenite & 100 & High & NA & $\begin{array}{c}(3098-3099=250 \mathrm{ppb} \\
\mathrm{Pt}+\mathrm{Pd})\end{array}$ \\
\hline H09 & 45 & $1264-1288$ & Fine to medium grained clinopyroxenite & 100 & High & NA & $\begin{array}{l}\text { (3101-3105; contain } \\
\text { moderate } \mathrm{Cu}, \mathrm{Zn})\end{array}$ \\
\hline H09 & 46 & $1288-1316$ & Fine to medium grained clinopyroxenite & 95 & High & Sphalerite? in veinlets & $\begin{array}{c}(3106-3108 ; 3199- \\
3200 ; 160 \mathrm{ppb} P \mathrm{t}+\mathrm{Pd})\end{array}$ \\
\hline H09 & 47 & $1316-1338$ & Fine to medium grained clinopyroxenite & 100 & Very High & Epidote veinlets @ 1332 feet. & NA \\
\hline
\end{tabular}




\begin{tabular}{|c|c|c|c|c|c|c|c|}
\hline Drill Hole & Box \# & $\begin{array}{l}\text { Interval } \\
\text { (Feet) }^{(1)}\end{array}$ & Rock Type(s) Present ${ }^{(2)}$ & $\begin{array}{l}\text { Estimated } \\
\text { Core } \\
\text { Recovery }^{(3)}\end{array}$ & $\begin{array}{l}\text { Estimated } \\
\text { Magnetite } \\
\text { Content }^{(4)}\end{array}$ & $\begin{array}{l}\text { Alteration or Mineralization } \\
\text { Present }^{(5)}\end{array}$ & $\begin{array}{l}\text { Niton Results } \\
\text { (AES Analyses) }^{(6)}\end{array}$ \\
\hline H09 & 48 & $1338-1360$ & $\begin{array}{l}\text { Massive homogenous clinopyroxenite; with } \\
\text { felsic porphyry fragment in core } \\
\text { Thin Section } 205008 @ 1350 \text { feet }\end{array}$ & 100 & High & $\begin{array}{l}\text { Chrysocolla @ 1352-1353 feet. } \\
\text { and 1356-1357 feet. but not } \\
\text { confirmed by Niton }\end{array}$ & NA \\
\hline H09 & 49 & $1360-1383$ & $\begin{array}{l}\text { Coarse clinopyroxenite with zones of semi- } \\
\text { massive magnetite; } \\
\text { Thin section } 205009 @ 1375 \text { feet. }\end{array}$ & 100 & Very High & $\begin{array}{c}\text { Semi-massive magnetite @ } \\
1373-1380 \text { feet. }\end{array}$ & NA \\
\hline H09 & 50 & $1383-1414$ & $\begin{array}{l}\text { Massive homogenous clinopyroxenite with } \\
\text { coarse splotches of magnetite }\end{array}$ & $35-100$ & High & NA & $\begin{array}{l}\text { (272855-858; no } \\
\text { anomalies) }\end{array}$ \\
\hline H09 & 51 & $1414-1437$ & Medium to coarse-grained clinopyroxenite & 100 & High & NA & (272859; no anomalies) \\
\hline H09 & 52 & $1437-1458$ & Medium to coarse-grained clinopyroxenite & 100 & High & $\begin{array}{l}\text { Vertical chlorite coated } \\
\text { fractures }\end{array}$ & $\begin{array}{l}\text { (272860-862 contain } \\
\text { low } \mathrm{Pd} / \mathrm{Pt} \text { anomalies })\end{array}$ \\
\hline H09 & 53 & $1458-1481$ & $\begin{array}{l}\text { Medium to coarse-grained clinopyroxenite } \\
\text { with laminar andesite dikes }\end{array}$ & 100 & High & $\begin{array}{l}\text { Andesite and felsic dikes with } \\
\text { chlorite alteration }\end{array}$ & $\begin{array}{l}\text { (272863-864=100 ppb } \\
\text { Pt+Pd @1464-1470ft.) }\end{array}$ \\
\hline H09 & 54 & $1481-1503$ & $\begin{array}{l}\text { Medium to coarse-grained clinopyroxenite } \\
\text { with patches of breccias dikes }\end{array}$ & 100 & Moderate & $\begin{array}{l}\text { Chlorite-biotite alteration } \\
\text { zones throughout interval }\end{array}$ & $\begin{array}{c}(272865-867=50-100 \\
\text { ppb Pt+Pd })\end{array}$ \\
\hline H09 & 55 & $1503-1526$ & $\begin{array}{l}\text { Medium to coarse-grained clinopyroxenite } \\
\text { with andesite @ } 1548 \text { and } 1526 \text { feet. }\end{array}$ & 100 & Moderate & NA & $\begin{array}{c}(272868-870=415 \mathrm{ppb} \\
\mathrm{Pt}+\mathrm{Pd})\end{array}$ \\
\hline H09 & 56 & $1526-1553$ & $\begin{array}{l}\text { Medium to coarse-grained clinopyroxenite } \\
\text { with dikes @ } 1548 \text { and } 1550 \text { feet. }\end{array}$ & 100 & High & NA & NA \\
\hline H09 & 57 & $1553-1578$ & $\begin{array}{l}\text { Broken and sheared clinopyroxenite with } \\
\text { numerous thin dikes }\end{array}$ & 100 & High & $\begin{array}{l}\text { Broken zone from 1572-1578 } \\
\text { feet. }\end{array}$ & $\begin{array}{l}\text { (272872-876; low } \\
\text { PGE+Cu) }\end{array}$ \\
\hline H09 & 58 & $1578-1601$ & $\begin{array}{l}\text { Broken and sheared clinopyroxenite with } \\
\text { numerous thin dikes }\end{array}$ & 100 & Moderate & NA & NA \\
\hline H09 & 59 & $1601-1624$ & Medium to coarse-grained clinopyroxenite & 100 & $\begin{array}{l}\text { Moderate to } \\
\text { High }\end{array}$ & NA & NA \\
\hline H09 & 60 & $1624-1646$ & $\begin{array}{l}\text { Broken and sheared clinopyroxenite with } \\
\text { numerous thin dikes and fractures }\end{array}$ & 100 & Moderate & $\begin{array}{l}\text { High angle chlorite-coated } \\
\text { fractures }\end{array}$ & NA \\
\hline H09 & 61 & $1646-1667$ & $\begin{array}{l}\text { Pyroxenite and gabbro with magnetite- } \\
\text { pyroxene intergrowths }\end{array}$ & 100 & High & NA & NA \\
\hline H09 & 62 & $1667-1689$ & $\begin{array}{l}\text { Pyroxenite and gabbro with magnetite- } \\
\text { pyroxene intergrowths }\end{array}$ & 100 & Moderate & $\begin{array}{c}\text { Quartz crystals in vug-like } \\
\text { cavities @ } 1682 \text { and } 1684 \text { feet. }\end{array}$ & NA \\
\hline H09 & 63 & $1689-1713$ & $\begin{array}{l}\text { Pyroxenite and gabbro with magnetite- } \\
\text { pyroxene intergrowths }\end{array}$ & 100 & High & $\begin{array}{l}\text { Massive magnetite @ 1711- } \\
1712 \text { feet. }\end{array}$ & $\begin{array}{c}24 \% \text { Fe in Niton @1712 } \\
\text { ft. }\end{array}$ \\
\hline H09 & 64 & $1713-1738$ & Pyroxenite & 100 & High & Shear zones oblique to core & NA \\
\hline
\end{tabular}




\begin{tabular}{|c|c|c|c|c|c|c|c|}
\hline Drill Hole & Box\# & $\begin{array}{l}\text { Interval }^{(\text {Feet })^{(1)}}\end{array}$ & Rock Type(s) Present ${ }^{(2)}$ & $\begin{array}{l}\text { Estimated } \\
\text { Core } \\
\text { Recovery }^{(3)}\end{array}$ & $\begin{array}{l}\text { Estimated } \\
\text { Magnetite } \\
\text { Content }^{(4)}\end{array}$ & $\begin{array}{c}\text { Alteration or Mineralization } \\
\text { Present }^{(5)}\end{array}$ & $\begin{array}{c}\text { Niton Results } \\
\text { (AES Analyses) }^{(6)}\end{array}$ \\
\hline H09 & 65 & $1738-1762$ & Pyroxenite & 100 & Moderate & $\begin{array}{l}\text { Near vertical fractures with } \\
\text { chlorite and epidote }\end{array}$ & $\begin{array}{c}\text { Moderate Co @ 1749- } \\
1751 \text { feet. }\end{array}$ \\
\hline H09 & 66 & $1762-1785$ & $\begin{array}{l}\text { Pyroxenite but with lamprophyre and } \\
\text { granodiorite dikes; } \\
\text { thin section } 205010 @ 1753 \text { feet. }\end{array}$ & 100 & Moderate & $\begin{array}{l}\text { Granodiorite @ 1778-1781 } \\
\text { feet. }\end{array}$ & NA \\
\hline H09 & 67 & $1785-1807$ & Interlocking pyroxenite and granodiorite & 100 & $\begin{array}{l}\text { Low- } \\
\text { Moderate }\end{array}$ & $\begin{array}{l}\text { Zeolite fracture fillings @ } 1802 \\
\text { ft. }\end{array}$ & NA \\
\hline H09 & 68 & $1807-1827$ & $\begin{array}{l}\text { Pyroxene gabbro with amphiboles in } \\
\text { fractures }\end{array}$ & 100 & Moderate & $\begin{array}{l}\text { High angle fractures with } \\
\text { pyrite, zeolites, and chlorite }\end{array}$ & $\begin{array}{c}\text { Moderate } \mathrm{Cu} \\
(272787-789=115 \mathrm{ppb} \\
\mathrm{Pt}+\mathrm{Pd})\end{array}$ \\
\hline H09 & 69 & $1827-1853$ & $\begin{array}{l}\text { Pyroxene gabbro with amphiboles in } \\
\text { fractures }\end{array}$ & 100 & Moderate & $\begin{array}{l}\text { Disseminated sulfides in } \\
\text { gabbro }\end{array}$ & $\begin{array}{l}\text { Moderate } \mathrm{Cu} \text {, and Mo } \\
\text { @ 1836-1838 feet.; } \\
(272880-882=74 \mathrm{ppb} \\
\mathrm{Pt}+\mathrm{Pd})\end{array}$ \\
\hline H09 & 70 & $1853-1875$ & $\begin{array}{l}\text { Pyroxene gabbro with abundant andesite } \\
\text { dikes at various intervals; Thin sections } \\
\mathbf{2 0 5 0 1 1} @ 1874 \mathrm{ft} \text {. and } 205012 \text { @1861 ft. }\end{array}$ & 100 & $\begin{array}{l}\text { Low- } \\
\text { Moderate }\end{array}$ & $\begin{array}{l}\text { Stockwork style fractures of } \\
\text { chlorite and epidote; } \\
\text { malachite @ } 1861 \text { feet. }\end{array}$ & Moderate $\mathrm{Cu}$ \\
\hline H09 & 71 & $1875-1897$ & Biotite gabbro and pyroxenite 50:50 & 100 & $\begin{array}{l}\text { Low- } \\
\text { Moderate }\end{array}$ & $\begin{array}{l}\text { Highly sheared high angle } \\
\text { fractures with calcite, stilbite } \\
\text { and analcite }\end{array}$ & NA \\
\hline H09 & 72 & $1897-1920$ & Back to classic clinopyroxenite & 100 & Moderate & $\begin{array}{l}\text { Andesite dike @ 1918-1919 } \\
\text { feet. }\end{array}$ & $\begin{array}{l}\text { Moderate Cu @ } 1918 \\
\text { feet. }\end{array}$ \\
\hline HO9 & 73 & 1920-1943 & $\begin{array}{l}\text { Alternating pyroxenite and gabbro with } \\
\text { disseminated pyrite in fractures }\end{array}$ & 100 & Moderate & $\begin{array}{c}\text { Pyrite infilling fractures @ } \\
\text { 1932-1933 feet. }\end{array}$ & $\begin{array}{c}\text { Moderate Cu @ 1932- } \\
1933 \mathrm{ft} .\end{array}$ \\
\hline H09 & 74 & $1943-1966$ & $\begin{array}{l}\text { Pyroxenite with thin gabbro/andesite } \\
\text { dikelets }\end{array}$ & 100 & Moderate & $\begin{array}{c}\text { Andesite dikes @ } 1948 \text { and } \\
1963 \text { feet. }\end{array}$ & $\begin{array}{l}\text { Moderate Cu @ } 1943 \\
\text { ft.; High Cu at } 1963 \mathrm{ft} .\end{array}$ \\
\hline H09 & 75 & $1966-1988$ & $\begin{array}{c}\text { Pyroxenite with thin gabbro/andesite } \\
\text { dikelets }\end{array}$ & 100 & High & $\begin{array}{l}\text { High angle andesite dikelets } \\
\text { contain abundant } \\
\text { disseminated sulfides, } \\
\text { including trace chalcopyrite }\end{array}$ & $\begin{array}{l}\text { High Cu at 1978-1979 } \\
\text { feet. }\end{array}$ \\
\hline HO9 & 76 & $\begin{array}{l}\text { 1988-2000 } \\
\text { END OF } \\
\text { HOLE }\end{array}$ & $\begin{array}{l}\text { Mainly pyroxenite with thin } \\
\text { gabbro/andesite dikelets } \\
\text { Thin section } 205013 \text { @ } 1963 \text { feet. }\end{array}$ & 100 & High & $\begin{array}{l}\text { High angle andesite dikelets } \\
\text { contain abundant epidote, } \\
\text { disseminated sulfides, }\end{array}$ & $\begin{array}{l}\text { Moderate Mo and Cu } \\
\text { @ 1992-1993 feet; high } \\
\text { Cu @ } 1990 \text { feet }\end{array}$ \\
\hline
\end{tabular}




\begin{tabular}{|c|c|c|c|c|c|c|c|}
\hline Drill Hole & Box \# & $\begin{array}{l}\text { Interval }^{(1)} \\
\text { (Feet) }^{(1)}\end{array}$ & Rock Type(s) Present ${ }^{(2)}$ & $\begin{array}{l}\text { Estimated } \\
\text { Core }^{(3)} \\
\text { Recovery }^{(3)}\end{array}$ & $\begin{array}{l}\text { Estimated } \\
\text { Magnetite } \\
\text { Content }^{(4)}\end{array}$ & $\begin{array}{l}\text { Alteration or Mineralization } \\
\text { Present }^{(5)}\end{array}$ & $\begin{array}{c}\text { Niton Results } \\
\text { (AES Analyses) }^{(6)}\end{array}$ \\
\hline $\mathrm{H} 07$ & 1 & $155-186$ & Pyroxenite & 70 & High & NA & High $\mathrm{Bi}$; Moderate $\mathrm{Pb}$ \\
\hline $\mathrm{H} 07$ & 2 & $186-216$ & Medium grained pyroxenite & 95 & High & NA & $\begin{array}{l}\text { Moderate Cu @209- } \\
211 \text { ft.; (03217- } \\
\text { 03222=Moderate Cu) }\end{array}$ \\
\hline $\mathrm{H} 07$ & 3 & $216-243$ & Medium grained pyroxenite & $80-90$ & Moderate & NA & $(03223-03224)$ \\
\hline $\mathrm{H} 07$ & 4 & $243-276$ & $\begin{array}{l}\text { Fine grained clinopyroxenite; with fine } \\
\text { grained feldspar porphyry? }\end{array}$ & $75-90$ & $\begin{array}{c}\text { Low- } \\
\text { Moderate }\end{array}$ & $\begin{array}{l}\text { High angle white calcite } \\
\text { stringers in fractures }\end{array}$ & $\begin{array}{c}\text { Moderate Cu @ } 276 \mathrm{ft} . \\
(03225-03230)\end{array}$ \\
\hline $\mathrm{H} 07$ & 5 & $276-307$ & $\begin{array}{l}\text { Coarse pyroxenite with thin gabbroic } \\
\text { dikelets }\end{array}$ & $95-100$ & Moderate & NA & $(03230-03234)$ \\
\hline $\mathrm{H} 07$ & 6 & $307-338$ & $\begin{array}{l}\text { Coarse pyroxenite with thin gabbroic } \\
\text { dikelets }\end{array}$ & 100 & High & $\begin{array}{c}\text { Pyrite bearing diopside-rich } \\
\text { zone @ } 331 \text { feet. }\end{array}$ & $\begin{array}{l}(272967-968=100 \mathrm{ppb} \\
\mathrm{Pt}+\mathrm{Pd}) \text { at } 331-338 \mathrm{ft} .\end{array}$ \\
\hline $\mathrm{H} 07$ & 7 & $338-371$ & $\begin{array}{l}\text { Coarse pyroxenite with thin gabbroic } \\
\text { dikelets }\end{array}$ & $95-100$ & Moderate & $\begin{array}{c}1 / 2 \text { inch fine pyrite zone @ } 349 \\
\text { feet. }\end{array}$ & $(272969-970)$ \\
\hline $\mathrm{H} 07$ & 8 & $371-411$ & $\begin{array}{l}\text { Sugary pyroxenite with slickensided fault } \\
\text { zone }\end{array}$ & $\begin{array}{c}23-100 ; \\
\text { average }=55\end{array}$ & High & $\begin{array}{l}\text { Joints are coated with talc- } \\
\text { chlorite layer }\end{array}$ & $\begin{array}{l}\text { Moderate Cu @ 317- } \\
375 \text { feet. in fine dike }\end{array}$ \\
\hline $\mathrm{H} 07$ & 9 & $411-435$ & Epidote veinlet zones in pyroxenite & 100 & Moderate & $\begin{array}{c}\text { Strong epidotization } \\
\text { (propylitic) }\end{array}$ & NA \\
\hline $\mathrm{H} 07$ & 10 & $435-469$ & Homogenous, fine grained pyroxenite & 100 & $\begin{array}{l}\text { Variable; } \\
\text { Moderate }\end{array}$ & $\begin{array}{c}\text { Strong epidotization } \\
\text { (propylitic); with apatite grains }\end{array}$ & NA \\
\hline $\mathrm{H} 07$ & 11 & $469-499$ & $\begin{array}{l}\text { Medium to coarse grained pyroxenite with } \\
\text { felsic streaks } \\
\text { Thin Section } 205014 \text { @ } 474 \text { feet. }\end{array}$ & 100 & $\begin{array}{l}\text { Variable; } \\
\text { Moderate }\end{array}$ & NA & NA \\
\hline $\mathrm{H} 07$ & 12 & $499-527$ & $\begin{array}{l}\text { Medium to coarse grained pyroxenite with } \\
\text { felsic streaks }\end{array}$ & 100 & High & Fine grained bands of andesite & NA \\
\hline $\mathrm{H} 07$ & 13 & $527-557$ & $\begin{array}{l}\text { Medium to coarse grained pyroxenite with } \\
\text { hornblende bands }\end{array}$ & 100 & High & Disseminated sulfide in $\mathrm{cpx}$ & $\begin{array}{l}\text { Moderate Cu @ 528- } \\
529 \text { feet. } \\
\text { (272974-975=195 ppb } \\
\text { Pt+Pd) }\end{array}$ \\
\hline $\mathrm{H} 07$ & 14 & $557-587$ & $\begin{array}{l}\text { Interlayered pyroxenite and andesite } \\
\text { Thin Section } 205015 \text { @575 feet. }\end{array}$ & 100 & $\begin{array}{l}\text { Moderate; } \\
\text { Variable }\end{array}$ & $\begin{array}{l}\text { Sulfide dusting in andesite; } \\
\text { epidote from } 575-585 \text { feet. }\end{array}$ & NA \\
\hline $\mathrm{H} 07$ & 15 & $587-616$ & $\begin{array}{l}\text { Medium grained pyroxenite } \\
\text { Thin Section } 205016 \text { @ } 608 \text { feet. }\end{array}$ & 100 & Low & $\begin{array}{l}\text { Sulfide dust in fine grained } \\
\text { phase }\end{array}$ & $\begin{array}{l}\text { Moderate Cu @ 608- } \\
\quad 610 \text { feet. }\end{array}$ \\
\hline $\mathrm{H} 07$ & 16 & $616-643$ & 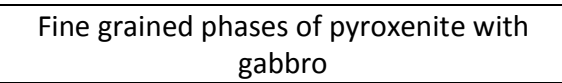 & 100 & $\begin{array}{l}\text { Moderate- } \\
\text { High }\end{array}$ & Talc-chlorite-coated joints & NA \\
\hline $\mathrm{H} 07$ & 17 & $643-671$ & $\begin{array}{l}\text { Fine grained phase at start and grading to } \\
\text { medium grained pyroxenite with depth }\end{array}$ & 100 & Moderate & NA & NA \\
\hline
\end{tabular}




\begin{tabular}{|c|c|c|c|c|c|c|c|}
\hline Drill Hole & Box \# & $\begin{array}{l}\text { Interval } \\
\text { (Feet) }^{(1)}\end{array}$ & Rock Type(s) Present ${ }^{(2)}$ & $\begin{array}{l}\text { Estimated } \\
\text { Core } \\
\text { Recovery }^{(3)}\end{array}$ & $\begin{array}{l}\text { Estimated } \\
\text { Magnetite } \\
\text { Content }^{(4)}\end{array}$ & $\begin{array}{c}\text { Alteration or Mineralization } \\
\text { Present }^{(5)}\end{array}$ & $\begin{array}{c}\text { Niton Results } \\
\text { (AES Analyses) }^{(6)}\end{array}$ \\
\hline $\mathrm{H} 07$ & 18 & $671-702$ & Medium to coarse grained pyroxenite & 100 & Moderate & NA & High Cu @ 685-687ft., \\
\hline $\mathrm{H} 07$ & 19 & $702-733$ & $\begin{array}{l}\text { Medium to coarse grained pyroxenite } \\
\text { With numerous thin fine grained dikes } \\
\text { Thin section } 205017 \text { @710 feet. }\end{array}$ & 100 & Moderate & $\begin{array}{l}\text { Contact zone of secondary } \\
\text { biotite with chlorite } \\
\text { (Propylitic) }\end{array}$ & NA \\
\hline $\mathrm{H} 07$ & 20 & $733-765$ & Medium to coarse grained pyroxenite & $85-100$ & $\begin{array}{l}\text { Low- } \\
\text { Moderate }\end{array}$ & NA & NA \\
\hline $\mathrm{H} 07$ & 21 & $765-792$ & Medium to coarse grained pyroxenite & $90-100$ & $\begin{array}{c}\text { Low- } \\
\text { Moderate }\end{array}$ & $\begin{array}{l}\text { Numerous high angle epidote } \\
\text { veins @ 790-792 feet. }\end{array}$ & $(272977=39 \mathrm{ppb} \mathrm{Pt}+\mathrm{Pd})$ \\
\hline $\mathrm{H} 07$ & 22 & $792-819$ & $\begin{array}{l}\text { Medium to coarse grained pyroxenite with } \\
\text { fine grained dikes; shear zone @ } 806-807 \mathrm{ft}\end{array}$ & 100 & Moderate & $\begin{array}{c}\text { Numerous high angle epidote } \\
\text { veins @ 794-796 feet. }\end{array}$ & $\begin{array}{l}\text { Moderate Cu @ 806- } \\
808 \text { feet. }\end{array}$ \\
\hline $\mathrm{H} 07$ & 23 & $819-856$ & $\begin{array}{l}\text { Medium to coarse grained pyroxenite with } \\
\text { fine grained dikes }\end{array}$ & $\begin{array}{c}45-100 ; \\
\text { average }=80\end{array}$ & Moderate & $\begin{array}{l}\text { High angle epidote veins @ } \\
830-836 \mathrm{ft} .\end{array}$ & NA \\
\hline $\mathrm{H} 07$ & 24 & $856-886$ & Medium to coarse grained pyroxenite & 100 & $\begin{array}{l}\text { Moderate- } \\
\text { High }\end{array}$ & $\begin{array}{l}\text { Disseminated sulfides @ 872- } \\
874 \text { feet. }\end{array}$ & NA \\
\hline $\mathrm{H} 07$ & 25 & $886-915$ & Medium to coarse grained pyroxenite & 100 & Moderate & $\begin{array}{c}\text { Epidote and trace sulfides @ } \\
\text { 908-911 feet. }\end{array}$ & NA \\
\hline $\mathrm{H} 07$ & 26 & $915-943$ & Medium to coarse grained pyroxenite & 100 & Moderate & $\begin{array}{l}\text { Chlorite-calcite fracture } \\
\text { surfaces @ 940-943 feet. }\end{array}$ & $\begin{array}{c}\text { (272980 }=30 \mathrm{ppb} \mathrm{Pt}+\mathrm{Pd} \\
\text { @ } 942 \text { feet) }\end{array}$ \\
\hline $\mathrm{H} 07$ & 27 & $943-972$ & Fine to medium grained pyroxenite & 100 & Moderate & $\begin{array}{l}\text { Chlorite-calcite fracture } \\
\text { surfaces @ 944-964 feet. }\end{array}$ & $\begin{array}{c}\text { (272981=33 ppb Pt+Pd } \\
@ 948-955 \text { feet) }\end{array}$ \\
\hline $\mathrm{H} 07$ & 28 & $972-1001$ & Fine to medium grained pyroxenite & 100 & Moderate & $\begin{array}{l}\text { Talc-chlorite-filled shear zones } \\
\text { in core @ 985-1001 }\end{array}$ & NA \\
\hline $\mathrm{H} 07$ & 29 & $1001-1029$ & Fine to medium grained pyroxenite & 100 & Moderate & $\begin{array}{l}\text { Talc-chlorite-filled shear zones } \\
\text { in core @ 1001-1021 }\end{array}$ & NA \\
\hline $\mathrm{H} 07$ & 30 & $1029-1059$ & $\begin{array}{l}\text { Fine to medium grained pyroxenite, but } \\
\text { with diorite phases }\end{array}$ & 100 & Moderate & NA & $(203235-237)$ \\
\hline $\mathrm{H} 07$ & 31 & $1059-1088$ & $\begin{array}{l}\text { Fine to medium grained pyroxenite, but } \\
\text { with diorite phases; much of core was split }\end{array}$ & 100 & $95-100$ & $\begin{array}{l}\text { Chloritized zones with sulfides } \\
\text { @ 1071-1074 feet. }\end{array}$ & $\begin{array}{c}\text { Moderate Cu @ 1071- } \\
1074 \text { feet. } \\
(032237-242)\end{array}$ \\
\hline $\mathrm{H} 07$ & 32 & $1088-1116$ & Fine to medium grained pyroxenite, & 100 & $95-100$ & NA & $(032243-245)$ \\
\hline $\mathrm{H} 07$ & 33 & $1116-1146$ & Fine to medium grained pyroxenite & 100 & $90-100$ & $\begin{array}{l}\text { Small chlorite-epidote veinlets } \\
\text { @ 1122-1133 }\end{array}$ & NA Run blocks in error \\
\hline
\end{tabular}




\begin{tabular}{|c|c|c|c|c|c|c|c|}
\hline Drill Hole & Box \# & $\begin{array}{l}\text { Interval } \\
\text { (Feet) }^{(1)}\end{array}$ & Rock Type(s) Present ${ }^{(2)}$ & $\begin{array}{l}\text { Estimated } \\
\text { Core } \\
\text { Recovery }^{(3)}\end{array}$ & $\begin{array}{l}\text { Estimated } \\
\text { Magnetite } \\
\text { Content }^{(4)}\end{array}$ & $\begin{array}{c}\text { Alteration or Mineralization } \\
\text { Present }^{(5)}\end{array}$ & $\begin{array}{c}\text { Niton Results } \\
\text { (AES Analyses) }^{(6)}\end{array}$ \\
\hline $\mathrm{H} 07$ & 34 & $1146-1191$ & Andesite dikes in pyroxenite & $60-100$ & Moderate & NA & $\begin{array}{l}\text { NA something wrong } \\
\text { with numbering } \\
\text { sequence }\end{array}$ \\
\hline $\mathrm{H} 07$ & 35 & $1191-1220$ & Pyroxenite but with leucocratic units & $75-100$ & Moderate & NA & $\begin{array}{l}\text { High Cu @ } 1219 \text { feet. } \\
\text { (272985-986=35 ppb } \\
\text { Pt+Pd @ } 1219 \text { feet) }\end{array}$ \\
\hline $\mathrm{H} 07$ & 36 & $1220-1248$ & $\begin{array}{l}\text { Light colored unit (diorite to monzonite) } \\
\text { for most of core box; upper part in contact } \\
\text { with pyroxenite }\end{array}$ & $75-100$ & Low & NA & (272987@1221=ND) \\
\hline $\mathrm{H} 07$ & 37 & $1248-1277$ & $\begin{array}{l}\text { Monzonite to } 166 \mathrm{ft} \text {; then back to } \\
\text { pyroxenite Thin section } 205018 @ 1266 \mathrm{ft} \text {. }\end{array}$ & 100 & Moderate & NA & $\begin{array}{l}\text { High Co @ } 1269 \text { ft; } \\
\text { Moderate Cu @ } 1266\end{array}$ \\
\hline $\mathrm{H} 07$ & 38 & $1277-1305$ & Pyroxenite but with fine grained phases & 100 & Moderate & $\begin{array}{l}\text { High angle carbonate veinlets } \\
\text { @ 1303-1305 feet }\end{array}$ & $\begin{array}{c}\text { Moderate Cu @ } 1303 \\
\text { ft. }\end{array}$ \\
\hline $\mathrm{H} 07$ & 39 & $1305-1335$ & Medium grained pyroxenite & 100 & Moderate & $\begin{array}{l}\text { High angle epidote veinlets @ } \\
1315 \text { feet. }\end{array}$ & $\begin{array}{l}\text { Moderate Pd @ } 1315 \\
\text { feet. }\end{array}$ \\
\hline $\mathrm{H} 07$ & 40 & $1335-1361$ & $\begin{array}{l}\text { Medium grained pyroxenite; with } \\
\text { pegmatoidal zone @ 1356-1359 ft. }\end{array}$ & 100 & Low & $\begin{array}{l}\text { Dark gray andesite cuts core } \\
\qquad 30^{\circ}\end{array}$ & NA \\
\hline $\mathrm{H} 07$ & 41 & 1361-1391 & Medium grained pyroxenite & 100 & Moderate & NA & NA \\
\hline $\mathrm{H} 07$ & 42 & $1391-1428$ & $\begin{array}{c}\text { Medium grained pyroxenite with andesite } \\
\text { phases }\end{array}$ & 100 & $\begin{array}{l}\text { Moderate- } \\
\text { High }\end{array}$ & $\begin{array}{l}\text { Pyrite and calcite from 1401- } \\
1411 \text { feet. }\end{array}$ & NA \\
\hline $\mathrm{H} 07$ & 43 & $1428-1457$ & $\begin{array}{l}\text { Medium grained pyroxenite with andesite } \\
\text { phases }\end{array}$ & $70-100$ & Moderate & $\begin{array}{l}\text { Trace sulfides in fine grained } \\
\text { phases @ 1448-1452 feet. }\end{array}$ & $\begin{array}{c}\text { Moderate Cu @1448- } \\
1452 \mathrm{ft} .\end{array}$ \\
\hline $\mathrm{H} 07$ & 44 & $1457-1486$ & $\begin{array}{l}\text { Medium grained pyroxenite with flow- } \\
\text { banded andesite phases }\end{array}$ & 100 & High & NA & NA \\
\hline $\mathrm{H} 07$ & 45 & $1486-1512$ & $\begin{array}{l}\text { Medium grained pyroxenite with thin } \\
\text { leucocratic phases }\end{array}$ & 100 & Moderate & Veins@1501-1503 feet & $(032246-247)$ \\
\hline $\mathrm{H} 07$ & 46 & $1512-1538$ & $\begin{array}{l}\text { Fragmental, fine grained pyroxenite } \\
\text { Thin Section } 205020 \text { @ } 1520 \text { feet. }\end{array}$ & 100 & Moderate & $\begin{array}{c}\text { Chlorite-pyrite veins @ } 1524 \\
\text { feet. }\end{array}$ & $\begin{array}{l}\text { Moderate Cu @ } 1524 \\
\text { feet.; (032248-253 are } \\
\text { splits AES core) }\end{array}$ \\
\hline $\mathrm{H} 07$ & 47 & $1538-1564$ & Medium grained pyroxenite & 100 & Moderate & NA & $(03253-56)$ \\
\hline $\mathrm{H} 07$ & 48 & $1564-1592$ & Medium grained pyroxenite & 100 & $\begin{array}{l}\text { Moderate- } \\
\text { High }\end{array}$ & $\begin{array}{l}\text { Chlorite stockwork fractures } \\
\text { @ 1575-1585 feet. }\end{array}$ & NA \\
\hline $\mathrm{H} 07$ & 49 & $1592-1621$ & $\begin{array}{l}\text { Medium grained pyroxenite with chlorite } \\
\text { alteration }\end{array}$ & 100 & Moderate & $\begin{array}{l}\text { Chlorite alteration throughout } \\
\text { core box }\end{array}$ & $(272984)$ \\
\hline
\end{tabular}




\begin{tabular}{|c|c|c|c|c|c|c|c|}
\hline Drill Hole & Box \# & $\begin{array}{l}\text { Interval } \\
\text { (Feet) }^{(1)}\end{array}$ & Rock Type(s) Present ${ }^{(2)}$ & $\begin{array}{l}\text { Estimated } \\
\text { Core }^{(3)} \\
\text { Recovery }^{(3)}\end{array}$ & $\begin{array}{l}\text { Estimated } \\
\text { Magnetite } \\
\text { Content }^{(4)}\end{array}$ & $\begin{array}{l}\text { Alteration or Mineralization } \\
\text { Present }^{(5)}\end{array}$ & $\begin{array}{c}\text { Niton Results } \\
\text { (AES Analyses) }^{(6)}\end{array}$ \\
\hline $\mathrm{H} 07$ & 50 & $1621-1651$ & Fine grained pyroxenite & 100 & $\begin{array}{l}\text { Moderate- } \\
\text { High }\end{array}$ & NA & $(272990-991)$ \\
\hline $\mathrm{H} 07$ & 51 & $1651-1676$ & Fine to medium grained pyroxenite & $50-100$ & $\begin{array}{l}\text { Moderate- } \\
\text { High }\end{array}$ & NA & $\begin{array}{l}\text { Core was cut but no } \\
\text { tags }\end{array}$ \\
\hline $\mathrm{H} 07$ & 52 & $1676-1704$ & Fine to medium grained pyroxenite & 100 & Moderate & $\begin{array}{l}\text { Chlorite carbonate high angle } \\
\text { veinlets @ 1698-1701 feet. }\end{array}$ & $\begin{array}{c}\text { Moderate Cu @ } 1680 \\
\mathrm{ft} .\end{array}$ \\
\hline $\mathrm{H} 07$ & 53 & $1704-1733$ & Fine to medium grained pyroxenite & 100 & $\begin{array}{l}\text { Moderate- } \\
\text { High }\end{array}$ & $\begin{array}{l}\text { High angle epidote veining @ } \\
1706-1709 \text { feet. }\end{array}$ & Very High V @ 1717 ft. \\
\hline $\mathrm{H} 07$ & 54 & $1733-1761$ & Fine to medium grained pyroxenite & 100 & High & NA & NA \\
\hline $\mathrm{H} 07$ & 55 & $1761-1788$ & $\begin{array}{l}\text { Pyroxenite-then gabbro--non-magnetic- } \\
\text { from } 1765-1775 \text {-then back to pyroxenite }\end{array}$ & 100 & Low & NA & NA \\
\hline $\mathrm{H} 07$ & 56 & $1788-1815$ & Fine to medium grained pyroxenite & 100 & Moderate & NA & $\begin{array}{c}(272992-994=150 \mathrm{ppb} \\
\mathrm{Pt}+\mathrm{Pd} @ 1813 \mathrm{ft} .\end{array}$ \\
\hline $\mathrm{H} 07$ & 57 & $1815-1842$ & Fine to medium grained pyroxenite & 100 & Moderate & $\begin{array}{c}\text { Epidote-carbonate veining @ } \\
1816-1817 \text { feet. } \\
\end{array}$ & NA \\
\hline $\mathrm{H} 07$ & 58 & $1842-1869$ & $\begin{array}{l}\text { Fine to medium grained biotite pyroxenite } \\
\text { Thin Section } 205021 \text { @ } 1859 \text { feet. } \\
\text { Thin section } 205022 \text { @ } 1868 \text { feet. }\end{array}$ & 100 & $\begin{array}{l}\text { Low- } \\
\text { Moderate }\end{array}$ & NA & $\begin{array}{l}\text { Very High Cu @ } 1868 \\
\text { feet.; native copper } \\
\text { found in thin section }\end{array}$ \\
\hline $\mathrm{H} 07$ & 59 & $1869-1897$ & Fine to medium grained pyroxenite & 100 & Moderate & NA & NA \\
\hline $\mathrm{H} 07$ & 60 & $1897-1925$ & Fine to medium grained pyroxenite & 100 & Moderate & Veins @ 1920-1925 feet. & $\begin{array}{l}\text { (3256-3260) All core } \\
\text { has been quartered }\end{array}$ \\
\hline $\mathrm{H} 07$ & 61 & $1925-1953$ & $\begin{array}{l}\text { Fine to medium grained pyroxenite; felsic } \\
\text { dike @ 1923-1928 feet. }\end{array}$ & 100 & Moderate & NA & $\begin{array}{l}\text { Moderate Cu @ 1922- } \\
1924 \text { ft. (03261-03265) } \\
\text { All core has been } \\
\text { quartered }\end{array}$ \\
\hline $\mathrm{H} 07$ & 62 & $1953-1982$ & Fine to medium grained pyroxenite & 100 & Moderate & NA & $\begin{array}{l}\text { (03266-03272) All core } \\
\text { has been quartered }\end{array}$ \\
\hline $\mathrm{H} 07$ & 63 & $\begin{array}{l}1982-2000 \\
\text { END OF } \\
\text { HOLE }\end{array}$ & Fine to medium grained pyroxenite & 100 & Moderate & NA & $\begin{array}{l}\text { (03272-03275) All core } \\
\text { has been quartered }\end{array}$ \\
\hline H08 & $1 \mathrm{~A}$ & $224-236$ & Fine grained pyroxenite & 100 & Moderate & $\begin{array}{l}\text { Chlorite-kaolinite alteration } \\
\text { along high angle fractures; } \\
\text { native copper @ } 228 \text { feet. }\end{array}$ & $\begin{array}{l}\text { High Cu @ 227-229 ft. } \\
\text { (3092-3093) }\end{array}$ \\
\hline $\mathrm{H} 08$ & $1 B$ & $236-246$ & $\begin{array}{c}\text { Gabbro begins at } 236.5 \text { feet; then back to } \\
\text { pyroxenite @ } 238.5 \text { feet. }\end{array}$ & $75-100$ & High & NA & Moderate copper @ \\
\hline
\end{tabular}




\begin{tabular}{|c|c|c|c|c|c|c|c|}
\hline Drill Hole & Box \# & $\begin{array}{l}\text { Interval } \\
\text { (Feet) }^{(1)}\end{array}$ & Rock Type(s) Present ${ }^{(2)}$ & $\begin{array}{l}\text { Estimated } \\
\text { Core } \\
\text { Recovery }^{(3)}\end{array}$ & $\begin{array}{l}\text { Estimated } \\
\text { Magnetite } \\
\text { Content }^{(4)}\end{array}$ & $\begin{array}{l}\text { Alteration or Mineralization } \\
\text { Present }^{(5)}\end{array}$ & $\begin{array}{l}\text { Niton Results } \\
\text { (AES Analyses) }^{(6)}\end{array}$ \\
\hline $\mathrm{H} 08$ & 2 & $246-279$ & Fine grained pyroxenite & $50-100$ & $\begin{array}{l}\text { Moderate- } \\
\text { High }\end{array}$ & $\begin{array}{l}\text { Feldspar-chlorite veinlets @ } \\
263-264 \mathrm{ft} .\end{array}$ & $\begin{array}{l}\text { Moderate Cu @ 263- } \\
264 \text { feet. }\end{array}$ \\
\hline H08 & 3 & $279-310$ & $\begin{array}{l}\text { Highly magnetic, fine to medium grained } \\
\text { pyroxenite } \\
\text { Thin Section } 205023 \text { @ } 306 \text { feet. }\end{array}$ & 100 & $\begin{array}{l}\text { High-Very } \\
\text { High }\end{array}$ & $\begin{array}{l}\text { High angle, quartz-epidote- } \\
\text { chlorite fractures @ 306-309 } \\
\text { ft. disseminated sulfides in } \\
\text { fractures }\end{array}$ & $\begin{array}{l}\text { Moderate Cu @ 306- } \\
\quad 309 \text { feet. }\end{array}$ \\
\hline $\mathrm{H} 08$ & 4 & $310-329$ & $\begin{array}{l}\text { Highly magnetic, fine to medium grained } \\
\text { pyroxenite }\end{array}$ & 100 & $\begin{array}{l}\text { Moderate- } \\
\text { High }\end{array}$ & $\begin{array}{c}\text { Thin quartz veinlets in } \\
\text { leucocratic zones @ 315-318ft }\end{array}$ & $\begin{array}{l}\text { Moderate Cu @ } 318 \mathrm{ft} . \\
\text { (3194-3197; but no Cu) }\end{array}$ \\
\hline $\mathrm{H} 08$ & 5 & $329-360$ & Fine to medium grained pyroxenite & 100 & Moderate & $\begin{array}{c}\text { Epidote sulfide veins @ } 331 \\
\text { feet. }\end{array}$ & High Cu @ 344 feet. \\
\hline $\mathrm{H} 08$ & 6 & $360-386$ & Fine to medium grained pyroxenite & $80-100$ & Moderate & $\begin{array}{l}\text { High angle fractures in-filled } \\
\text { with disseminated sulfides @ } \\
380 \text { feet. }\end{array}$ & $\begin{array}{l}\text { Moderate Cu @ } 380 \\
\text { feet. }\end{array}$ \\
\hline $\mathrm{H} 08$ & 7 & $386-413$ & $\begin{array}{l}\text { Fine to medium grained pyroxenite; gabbro } \\
\text { begins @ } 408 \mathrm{ft} .\end{array}$ & $80-100$ & $\begin{array}{l}\text { Low- } \\
\text { Moderate }\end{array}$ & $\begin{array}{l}\text { High angle veinlets @ } 402 \text { and } \\
406 \text { feet. }\end{array}$ & $\begin{array}{c}\text { Moderate } \mathrm{Cu} \text { and Zn @ } \\
402 \text { feet. }\end{array}$ \\
\hline $\mathrm{H} 08$ & 8 & $413-443$ & Medium grained pyroxene gabbro & $50-100$ & Nonmagnetic & Veinlets @ 416 and 422 feet. & Moderate Cu @ 422 ft. \\
\hline $\mathrm{H} 08$ & 9 & $443-475$ & $\begin{array}{l}\text { Medium grained pyroxene gabbro } \\
\text { Thin section } 205024 \text { @ } 472 \text { feet. }\end{array}$ & $90-100$ & $\begin{array}{l}\text { Low- } \\
\text { Nonmagnetic }\end{array}$ & $\begin{array}{l}\text { Numerous high angle fractures } \\
\text { @ 445-456 feet. }\end{array}$ & $\begin{array}{l}\text { Moderate } \mathrm{Cu} @ 445 \mathrm{ft} . ; \\
\text { Moderate Cu and Zn @ } \\
\quad 452 \text { feet. }\end{array}$ \\
\hline $\mathrm{H} 08$ & 10 & $475-521$ & $\begin{array}{l}\text { Medium grained pyroxene gabbro to } 512 \\
\text { ft.; then back into pyroxenite }\end{array}$ & $\begin{array}{l}10-60 \\
\text { Lowest } \\
\text { recorded }\end{array}$ & $\begin{array}{l}\text { Low- } \\
\text { Moderate }\end{array}$ & $\begin{array}{l}\text { High angle small veinlets } \\
\text { pervasive when back into } \\
\text { pyroxenite }\end{array}$ & $\begin{array}{l}\text { Low Zn and Ni @ } 512 \\
\mathrm{ft} . ; \text { High Cd and Cu and } \\
\text { Moderate Mo @ } 513 \mathrm{ft} .\end{array}$ \\
\hline $\mathrm{H} 08$ & 11 & $521-553$ & Fine to medium grained pyroxenite & $\begin{array}{l}80-100 \\
\text { Variable }\end{array}$ & Moderate & NA & NA \\
\hline $\mathrm{H} 08$ & 12 & $\begin{array}{l}553-577 \\
\text { END OF } \\
\text { HOLE }\end{array}$ & $\begin{array}{l}\text { Fine to medium grained magnetic } \\
\text { pyroxenite }\end{array}$ & $\begin{array}{l}50-100 \\
\text { Variable }\end{array}$ & High & NA & NA \\
\hline $\mathrm{HO4}$ & 16 & $296-365$ & $\begin{array}{l}\text { Composited fine and coarse grained } \\
\text { pyroxenite; logged as fine grained gabbro; } \\
\text { Thin section } 205025 \text { @ } 355 \text { feet. }\end{array}$ & $30-85$ & $\begin{array}{l}\text { Low to } \\
\text { Nonmagnetic }\end{array}$ & $\begin{array}{l}\text { Magmatic sulfides at 355-360 } \\
\text { feet. }\end{array}$ & $\begin{array}{l}\text { Moderate Cu, V, and } \\
\text { High Ti @ 355-360 ft. } \\
\text { (205698-706; most of } \\
\text { core was quartered) }\end{array}$ \\
\hline $\mathrm{H} 04$ & 17 & $365-419$ & $\begin{array}{l}\text { Composited fine grained mafic intrusion } \\
\text { (Gabbro?) }\end{array}$ & $25-75$ & $\begin{array}{c}\text { Low to } \\
\text { Nonmagnetic }\end{array}$ & NA & $\begin{array}{c}\text { High Cu @ } 374 \mathrm{ft} . \\
\text { Moderate Cu and V @ } \\
401 \mathrm{ft} .(205708-205716 ; \\
\text { all core was quartered) }\end{array}$ \\
\hline
\end{tabular}




\begin{tabular}{|c|c|c|c|c|c|c|c|}
\hline Drill Hole & Box \# & $\begin{array}{l}\text { Interval }^{(\text {Feet })^{(1)}}\end{array}$ & Rock Type(s) Present ${ }^{(2)}$ & $\begin{array}{l}\text { Estimated } \\
\text { Core } \\
\text { Recovery }^{(3)} \\
\end{array}$ & $\begin{array}{l}\text { Estimated } \\
\text { Magnetite } \\
\text { Content }^{(4)} \\
\end{array}$ & $\begin{array}{l}\text { Alteration or Mineralization } \\
\text { Present }^{(5)}\end{array}$ & $\begin{array}{l}\text { Niton Results } \\
\text { (AES Analyses) }^{(6)}\end{array}$ \\
\hline $\mathrm{HO4}$ & 18 & $419-460$ & $\begin{array}{l}\text { Composited fine grained mafic intrusion } \\
\text { (Gabbro?); Thin section } 205026 @ 439 \mathrm{ft} \text {. }\end{array}$ & 65 & $\begin{array}{l}\text { Low to } \\
\text { Nonmagnetic }\end{array}$ & $\begin{array}{l}\text { Thin and isolated, high angle } \\
\text { factures with chlorite and } \\
\text { epidote; various locations }\end{array}$ & $\begin{array}{c}\text { Moderate Cu, Co and } \\
\text { Zn @ } 450 \text { ft.; } \\
(205717-205723)\end{array}$ \\
\hline $\mathrm{HO4}$ & 19 & $\begin{array}{l}460-468 \\
\text { END OF } \\
\text { HOLE? }\end{array}$ & $\begin{array}{l}\text { Composited fine grained mafic intrusion } \\
\text { (Gabbro?); }\end{array}$ & 70 & $\begin{array}{l}\text { Low to } \\
\text { Nonmagnetic }\end{array}$ & $\begin{array}{l}\text { Thin and isolated, high angle } \\
\text { factures with chlorite and } \\
\text { epidote; various locations }\end{array}$ & $\begin{array}{c}\text { Moderate Cu and Cr @ } \\
\text { 464-466 feet. }\end{array}$ \\
\hline $\mathrm{H} 16$ & 1 & $256-308$ & Purple-hued banded hornfels & 45 & Nonmagnetic & NA & NA \\
\hline $\mathrm{H} 16$ & 2 & $308-370$ & $\begin{array}{l}\text { Purple-hued banded hornfels from } \\
\text { argillaceous sediments }\end{array}$ & 40 & Nonmagnetic & NA & NA \\
\hline $\mathrm{H} 16$ & 3 & $370-431$ & $\begin{array}{l}\text { Purple-hued banded hornfels from } \\
\text { argillaceous sediments; with andesite dikes }\end{array}$ & 45 & Nonmagnetic & NA & $\begin{array}{l}\text { Moderate Zn in } \\
\text { fractures @ } 385\end{array}$ \\
\hline $\mathrm{H} 16$ & 4 & $431-487$ & $\begin{array}{l}\text { Purple-hued banded hornfels from } \\
\text { argillaceous sediments; with andesite dikes }\end{array}$ & 80 & Nonmagnetic & NA & NA \\
\hline H16 & 5 & $487-515$ & $\begin{array}{c}\text { Purple-hued banded hornfels from } \\
\text { argillaceous sediments }\end{array}$ & $90-100$ & Nonmagnetic & NA & NA \\
\hline H16 & 6 & $515-549$ & $\begin{array}{l}\text { Purple-hued banded hornfels from } \\
\text { argillaceous sediments; nearly complete } \\
\text { core recovery except in fault zones }\end{array}$ & $50-100$ & $\begin{array}{l}\text { Weakly } \\
\text { magnetic }\end{array}$ & NA & NA \\
\hline H16 & 7 & $549-581$ & $\begin{array}{c}\text { Purple-hued banded hornfels from } \\
\text { argillaceous sediments } \\
\text { Thin section } 205027 \text { @ } 581 \text { feet. }\end{array}$ & 100 & $\begin{array}{l}\text { Weakly } \\
\text { magnetic }\end{array}$ & NA & NA \\
\hline H16 & 8 & $\begin{array}{l}581-601 \\
\text { END OF } \\
\text { HOLE }\end{array}$ & $\begin{array}{l}\text { Purple-hued banded hornfels from } \\
\text { argillaceous sediments; bands of marble }\end{array}$ & 85 & $\begin{array}{l}\text { Weakly } \\
\text { magnetic }\end{array}$ & NA & NA \\
\hline $\mathrm{H} 12$ & 1 & $254-294$ & $\begin{array}{l}254-280 \text { believed to be large glaciogenic } \\
\text { boulder; then } 280-294 \text { is weakly magnetic } \\
\text { gabbro Thin Section } 205028 @ \mathbf{2 8 2} \mathbf{f t} \text {. }\end{array}$ & $65-100$ & $\begin{array}{l}\text { Weakly } \\
\text { magnetic }\end{array}$ & NA & NA \\
\hline $\mathrm{H} 12$ & 2 & 294-315 & $\begin{array}{l}\text { Medium grained, pyroxene-rich gabbro } \\
205029 \text { Thin Section plug @ } 312 \text { feet-but } \\
\text { no thin section not made }\end{array}$ & 75 & $\begin{array}{l}\text { Weakly } \\
\text { magnetic }\end{array}$ & $\begin{array}{l}\text { Abundant epidote clots in } \\
\text { gabbro zones }\end{array}$ & $\begin{array}{l}\text { Very High Cu @ } 312 \\
\text { feet. }\end{array}$ \\
\hline $\mathrm{H} 12$ & 3 & $315-336$ & Medium grained, pyroxene-rich gabbro & 80 & $\begin{array}{l}\text { Weakly } \\
\text { magnetic }\end{array}$ & $\begin{array}{l}\text { Disseminated sulfides in high } \\
\text { angle carbonate-bearing } \\
\text { fractures }\end{array}$ & NA \\
\hline $\mathrm{H} 12$ & 4 & $336-356$ & Altered, greenish medium grained gabbro & $80-100$ & $\begin{array}{l}\text { Weakly } \\
\text { magnetic }\end{array}$ & $\begin{array}{l}\text { Entire gabbro section in box is } \\
\text { distinctly, hydrothermally } \\
\text { altered (Propylitic) }\end{array}$ & $\begin{array}{l}\text { Very High Cu @ } 346 \\
\text { feet. }\end{array}$ \\
\hline $\mathrm{H} 12$ & 5 & $356-378$ & Altered, greenish medium grained gabbro & $80-100$ & $\begin{array}{l}\text { Weakly } \\
\text { magnetic }\end{array}$ & $\begin{array}{l}\text { Gabbro is hydrothermally } \\
\text { altered }\end{array}$ & $\begin{array}{c}\text { (3130-3129) } \\
\text { All core quartered }\end{array}$ \\
\hline
\end{tabular}




\begin{tabular}{|c|c|c|c|c|c|c|c|}
\hline Drill Hole & Box \# & $\begin{array}{l}\text { Interval } \\
\text { (Feet) }^{(1)}\end{array}$ & Rock Type(s) Present ${ }^{(2)}$ & $\begin{array}{l}\text { Estimated } \\
\text { Core } \\
\text { Recovery }^{(3)}\end{array}$ & $\begin{array}{l}\text { Estimated } \\
\text { Magnetite } \\
\text { Content }^{(4)}\end{array}$ & $\begin{array}{l}\text { Alteration or Mineralization } \\
\text { Present }^{(5)}\end{array}$ & $\begin{array}{l}\text { Niton Results } \\
\text { (AES Analyses) }^{(6)}\end{array}$ \\
\hline $\mathrm{H} 12$ & 6 & $378-400$ & Medium grained, clinopyroxene gabbro & 100 & $\begin{array}{l}\text { Weakly } \\
\text { magnetic }\end{array}$ & $\begin{array}{l}\text { Feldspar segregations @ 408- } \\
409 \text { and } 412-413 \text { feet. }\end{array}$ & $\begin{array}{l}\text { Moderate Cu @ 412- } \\
\quad 413 \text { feet. }\end{array}$ \\
\hline $\mathrm{H} 12$ & 7 & $400-417$ & Medium grained, clinopyroxene gabbro & 100 & $\begin{array}{l}\text { Weakly } \\
\text { magnetic }\end{array}$ & NA & $\begin{array}{c}\text { (272921-922; } 150 \text { and } \\
158 \mathrm{ppm} \mathrm{Cu})\end{array}$ \\
\hline $\mathrm{H} 12$ & 8 & $417-445$ & Medium grained, clinopyroxene gabbro & 100 & $\begin{array}{l}\text { Weakly } \\
\text { magnetic }\end{array}$ & NA & NA \\
\hline $\mathrm{H} 12$ & 9 & $445-468$ & Medium grained, clinopyroxene gabbro & 100 & $\begin{array}{l}\text { Weakly } \\
\text { magnetic }\end{array}$ & NA & $\begin{array}{c}(272925-272927 \\
\text { contain 61-276 ppm } \\
\text { Cu) } \\
\end{array}$ \\
\hline $\mathrm{H} 12$ & 10 & $468-490$ & $\begin{array}{l}\text { Fresh, medium grained, clinopyroxene } \\
\text { gabbro }\end{array}$ & 100 & $\begin{array}{l}\text { Weakly } \\
\text { magnetic }\end{array}$ & NA & NA \\
\hline $\mathrm{H} 12$ & 11 & $490-514$ & $\begin{array}{l}\text { Fresh, medium grained gabbro but fine } \\
\text { grained felsic phase present also }\end{array}$ & 100 & Moderate & NA & $\begin{array}{c}\text { (272928-272929 } \\
\text { contain } 252 \text { and } 147 \\
\text { ppm Cu; } 31 \text { and } 37 \mathrm{ppb} \\
\text { PGE) from } 507-514 \mathrm{ft} \text {. }\end{array}$ \\
\hline $\mathrm{H} 12$ & 12 & $514-537$ & $\begin{array}{l}\text { Fresh, medium grained gabbro but fine } \\
\text { grained phase present also }\end{array}$ & 100 & Moderate & NA & $\begin{array}{c}(272930-272933 \\
\text { contain 196-402 ppm } \\
\text { Cu) }\end{array}$ \\
\hline $\mathrm{H} 12$ & 13 & $537-560$ & $\begin{array}{l}\text { Fresh, medium grained, clinopyroxene } \\
\text { gabbro }\end{array}$ & 100 & Moderate & NA & $\begin{array}{c}\text { (272934 contains } 686 \\
\text { ppm Cu) }\end{array}$ \\
\hline $\mathrm{H} 12$ & 14 & $560-591$ & Xenoliths of pyroxenite in the gabbro & 100 & Moderate & NA & High V @ 588-591 \\
\hline $\mathrm{H} 12$ & 15 & $\begin{array}{l}591-637 \\
\text { END OF } \\
\text { HOLE }\end{array}$ & Alkali leucratic zone along with gabbro0 & 100 & $\begin{array}{l}\text { Weak- } \\
\text { Moderate }\end{array}$ & $\begin{array}{l}\text { Xenoliths of pyroxenite in } \\
\text { gabbro, implying magmatic } \\
\text { stoping }\end{array}$ & $\begin{array}{c}\text { Moderate to } \mathrm{High} \mathrm{Ni} \\
\text { and Moderate } \mathrm{Cr} \text { from } \\
620-637 \text { feet. }\end{array}$ \\
\hline $\mathrm{H} 14$ & 1 & $92-500$ & $\begin{array}{c}\text { Skeleton core, in down-hole sequence: } \\
\text { hornblende gabbro, minor peridotite and } \\
\text { pyroxenite then gabbro again, then } \\
\text { monzodiorite, peridotite and finally gabbro } \\
\text { at TOD }\end{array}$ & $\begin{array}{l}\text { Variable } 40- \\
\quad 100\end{array}$ & Weak & NA & $\begin{array}{l}\text { Very High } \mathrm{Cr} \text { at } 455 \text { feet } \\
\text { (in peridotite) }\end{array}$ \\
\hline $\mathrm{H} 17$ & 1 & $240-530$ & $\begin{array}{l}\text { Skeleton core, in down-hole sequence: } \\
\text { eolian silt, cobbles and boulders sans, peat, } \\
\text { and finally hard pyroxenite @ } 460 \text { feet; } \\
\text { Biotite pyroxenite all the way to TD. }\end{array}$ & $\begin{array}{l}\text { Variable } 20- \\
\quad 100\end{array}$ & $\begin{array}{l}\text { Weak- } \\
\text { Moderate }\end{array}$ & NA & NA \\
\hline $\mathrm{H} 10$ & 1 & $\begin{array}{c}205-532 \\
E O H @ 532 f\end{array}$ & $\begin{array}{l}\text { Skeleton core, in down-hole sequence: } \\
\text { sand and gravel until } 230 \text {; then magnetic } \\
\text { pyroxenite to } 460 \text {; then gabbro, diorite, } \\
\text { and 'andesite' and back to pyroxenite }\end{array}$ & $50-100$ & $\begin{array}{l}\text { Weak- } \\
\text { Moderate }\end{array}$ & NA & NA \\
\hline
\end{tabular}




\begin{tabular}{|c|c|c|c|c|c|c|c|}
\hline Drill Hole & Box\# & $\begin{array}{l}\text { Interval } \\
\text { (Feet) }^{(1)}\end{array}$ & Rock Type(s) Present ${ }^{(2)}$ & $\begin{array}{l}\text { Estimated } \\
\text { Core } \\
\text { Recovery }^{(3)}\end{array}$ & $\begin{array}{l}\text { Estimated } \\
\text { Magnetite } \\
\text { Content }^{(4)}\end{array}$ & $\begin{array}{c}\text { Alteration or Mineralization } \\
\text { Present }^{(5)}\end{array}$ & $\begin{array}{c}\text { Niton Results } \\
\text { (AES Analyses) }^{(6)}\end{array}$ \\
\hline $\mathrm{H} 11$ & 1 & $159-500$ & $\begin{array}{c}\text { Skeleton core, in down-hole sequence: } \\
\text { pyroxenite all the way to the bottom of the } \\
\text { hole }\end{array}$ & $45-100$ & $\begin{array}{l}\text { Weak- } \\
\text { Moderate }\end{array}$ & NA & NA \\
\hline
\end{tabular}

(1) Interval estimates are rounded to the nearest foot

(2) Rock types assigned are on the basis of mineralogical and textural observations at GMC; selectively augmented by descriptions of Whaley and Bray (1959) and PRGCl thin section observations; Some rock units identified at the GMC changed because of what was observed in thin section. Thin section locations taken by PRGCl in bold. This particularly true of finer grained units.

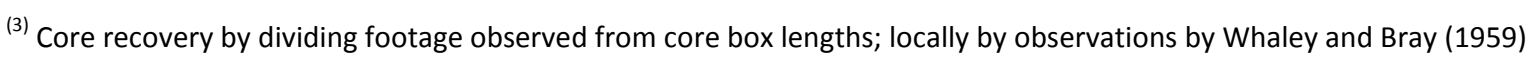

(4) Estimate based on use of PRGCI magnet survey @ GMC facility; Weak=<8.0\% iron; Moderate=8-12\% iron; High=12-15\% iron; and very high $=>15 \%$ iron. More-or-less consistent with iron content estimated by Humble geologists but not always so.

${ }^{(5)}$ Alteration based solely on PRGCI observations at GMC and petrographic analysis of thin sections

(6) Niton results expressed qualitatively; e.g., For copper: moderate $=>200$ ppm $<1,000$ ppm; high=>1,000 ppm; $<5,000$ ppm; very high >5,000 ppm. For molybdenum: moderate=>20 ppm; $<40$ ppm; High=>40 ppm; $<400$ ppm; very high $>400$ ppm. For bismuth: Moderate $=.10 \mathrm{ppm} ;<50 \mathrm{ppm}$; high=>50 ppm; $<150 \mathrm{ppm}$; very high $>150 \mathrm{ppm}$. For vanadium: moderate $=>500 \mathrm{ppm} ;<1,000 \mathrm{ppm}$; high $=>1,000$ ppm; $<10,000$ ppm; very high $=>10,000$. For zinc: moderate $>200$ ppm; $<500$ ppm; high $=>500$ ppm.; $<1,000$ ppm; very high=>1,000 ppm. For tungsten: moderate $=>100 \mathrm{ppm} ;<1,000 \mathrm{ppm}$; high=>1,000 ppm. For cobalt: moderate=>50 ppm; $<500 \mathrm{ppm}$; high $=>500 \mathrm{ppm}$. Numbers in parentheses are those sample number intervals analyzed mainly by AES, but perhaps by others, for which PRGCl did not have analytical data. When numbers in parentheses do not have values, that can mean either that no anomalies were detected or they were not found in data files, but left in table pending acquisition of that data 